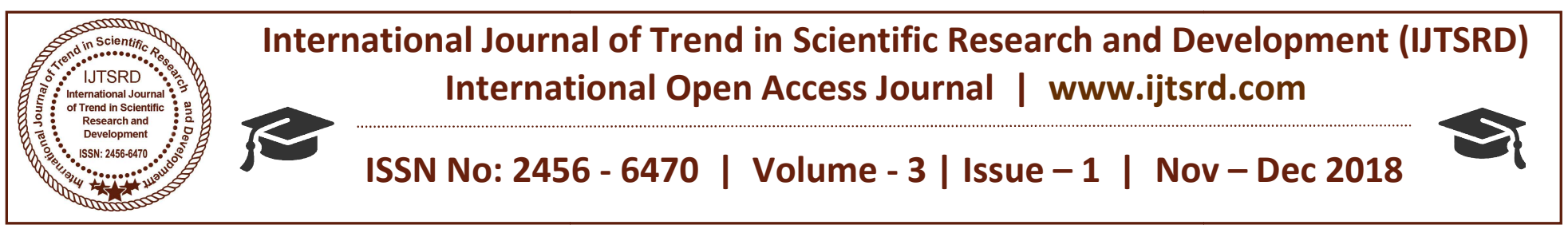

\title{
Functions of Cohesive Devices in Text Comprehension and Writing
}

\author{
Sunday Sule Emah PhD, Clement Gowon Omachonu PhD \\ Department of Arts Education, \\ Kogi State University, Anyigba, Nigeria
}

\begin{abstract}
This paper discusses the functions of cohesive relations in text. Cohesion is the singular factor that enables spoken or written document to "stick together." Therefore, we examined the concepts of coreferentiality (concept of text), text and the user, cohesion as a bond of text and the roles of transitional signals in text comprehension and in writing. The paper opines that sensitivity to cohesive relations that exist among the linguistic elements of any written text facilitates understanding of such texts. This is because readers are adequately kept on track when the writer posts notice of directions using transitional signals. The reader, as an active collaborator with the writer, is a major player in the literary game. Therefore, the text must cohesively hang together to enable him to "trust the text enough" so as to make sense of it. It also that inability to identify the functions of anaphoric and cataphoric ties in a text hinders adequate comprehension of it. Anaphoric tie points listeners or readers back to what has been said before, while cataphoric tie sensitizes them to on-coming information.
\end{abstract}

\section{KEY WORDS: Cohesion, text, comprehension, writing}

\section{INTRODUCTION}

Texts are written for various purposes. It could be to educate, entertain, inform, create an impression and for very many other reasons. Osundare makes a suitable remark about the style of a writer that "the audience of a literary communicator is potential. Those of the oral communicator are actual. While the oral performer can adapt or even change his style to suit the emotional temperament and intellectual complexion of his audience, the writer's style is relatively fixed, being subject to the permanence of print" (Osundare, 138).
Thus, unlike the oral performer, a writer cannot take the advantage of the audience's presence and immediate criticism to amend the original product, nor can the audience seek instantaneous clarification of a point not intelligibly made. This situation calls for adequate clarity of expression in writing. The bedrock of this clarity is sensitivity to the network of cohesive relations. Effective writing and efficient comprehension are functions of cohesive relations that exist among the linguistic elements of any written text.

In writing, cohesion is the use of repetition, transitional expressions, and other devices called cohesive cues to guide readers and show how the parts of composition relate to one another. Peter Clark makes this distinction between coherence and cohesion in a text: "when the big parts fit, we call that good feeling coherence; when sentences connect, we call it cohesion". In a similar sense, Mary Kennedy says "At its simplest, cohesion refers to the ways in which texts are "stuck together"... the ways in which sentences are linked or connected by various linguistic and semantic ties". In the works of Wayne and Marshall, "Cohesion is an explicit set of "hooks" and "ties" that ensures a reader's interest and comprehension. Cohesion is the result of giving readers the right kind of explicit help in figuring out the design. Cohesion gives readers the clues for discovering coherence". Indah Wardaty quoting Hinkel (2001) has this to say "cohesion is regarded as an essential textual component not only to create organized text, but also to portray the content of any write-up comprehensibly to the reader." He affirmed that when sentences, ideas and details fit together clearly, the reader can follow along easily.

What makes news reports of a journalist interesting? What makes the lecture notes of a lecturer or teacher 
hang together to make a unified whole? What makes an audience wish that a political orator should not descend from the podium? It is the bond of text created by cohesive relationships.

What then is text? Is it a phrase, a clause, a conglomeration of unrelated sentences, just a string of sentences, or simply a large grammatical unit? Text is a semantic phenomenon that is realizable by the sentences. A sentence is not necessarily a text, but it is possible for a sentence to be a text. Halliday and Hasan state that the term "text" is used in linguistics to refer to:

Any passage, spoken or written, of whatever length, that does form a unified whole. It could be a prose or verse, dialogue or monologue. It may be anything from a single proverb to a whole play, from a momentary cry for help to an all-day discussion on a committee (Halliday and Hasan, 1).

A text is a unit of language in use. It is not a grammatical unit like a clause, a sentence, and it is not defined by its size. A text is best regarded as a semantic unit; a unit not of form but of meaning. Thus, it is related to a clause or sentence not by size but by realization, the coding of one symbolic system in another. A text does not consists of sentences, it is realized by or encoded in, sentences.

\section{Text and the User}

The reader is the user of text par excellence. It is he or she who acquired the products of someone else's literary activity, and by consuming ("reading") them, satisfies a personal need, and indirectly, provides the author, the producer of the text, with feedback. Authors and readers have something in common as they collaborate with each other in the literary "market". The intentions of the producer (writer) as well as the consumer's (reader's ability) to comprehend must be respected.

Fareed and Hasan (2017:6) give a vivid description of the term "text" that the meaning and unity of text are well represented by the textual features of (wellformedness and interpretability), which in turn refers to writer's preferences of certain linguistic patterns to transfer their ideas, thoughts and beliefs to people. People here refers to the readers or listeners who are supposed to decode or interpret the transferred intended meanings in the form of texts and discourses.
In the same vein, quoting Widows (2007) they point out that "any piece of language that has been produced for a communicative purpose is to be recognized as a text. In other words, getting or delivering a message across is the central function of the text. They opined that any text can be explained in terms of three important characteristics: First, text is considered as a meaning, i.e. although it is made of words and sentences, it is really made of meanings; second, it has to be coded in something in order to be communicated, but as a thing in itself, a text is essentially a semantic unit; and third, we need to see the text as a product and the text as process and to keep both these aspect in focus (Halliday, 1994:13 in Fareed and Hasan, 2017)

In the literary world of producing and consuming, one doesn't just buy a book: one buys an author to take home with him. The work that the author has done in producing the text has to be supplemented and completed by you, the reader. Reading is a collaborative activity, taking place between author and reader: reading is an innovative process of active recreation, not just the passive, pre-set and predetermined use of some "recreational facility". "[A novel] is made in the head, and has to be remade in the head by whoever reads it, who will always remake it differently (Byatt, in Mev, 237). It then means that the reader, as an active collaborator, is a major player in the literary game. Therefore, the text should cohesively hang together to enable the reader to "trust the text enough" so as to make sense of it. In other words, the text must contain enough cohesive ties that could foster understanding of it by the consumer (reader).

\section{Cohesion as a Bond of Text}

Cohesion is the act of sticking together. It is the term for the quality of a text such that it appears as a single unit, not as a random sequence of thoughts or sentences. Cohesion is achieved by a number of devices or ties present in a text. A tie refers to a single instance of cohesion, a term for one occurrence of a pair of cohesively related items. This is called a tie. In the words of Halliday and Hasan:

Cohesion occurs where the interpretation of an element in the discourse is dependent on the successful interpretation of another. The one presupposes the other in the sense that it cannot be effectively decoded except by reference (recourse) to it (Halliday \& Hasan, 4). 
The notion of cohesion is similar to that of a "tie". Cohesive relation is a set when the interpretation of a presupposing element is dependent on that of a presupposed, both elements being at least potentially integrated into a text. It is this presupposition, and the fact that it is resolved, that provides cohesion between the two sentences, and in so doing creates text.

There are different kinds of cohesive relations. They include reference, ellipsis, substitution, conjunction and lexical cohesion. As earlier noted, the potential of cohesion lies in the systematic resources of these relations that are inbuilt in language. As seen from the given examples, a word can take on a cohesion force only if there is some explicit referent for it within reach. This is to say that cohesion lies in the relation that can be set up between two referents - the presupposing and the presupposed items, alternatively referred to as the "presupposed" and the "antecedent" respectively. We must see cohesion, therefore, as the linguistic means which brings text into being and enables it to function as a single meaningful unit. On a wider scope, cohesive relations are classified into two broad categories.

A. Grammatical cohesion - this embodies references, substitution and ellipsis; and

B. Lexical cohesion - this refers to the way in which related words are chosen to link elements in a text. There are two forms: repetition and collocation. Repetition uses the same word, or synonyms, antonyms, etc. For example, "which dress are you going to wear?" - "I will wear my green frock", uses the synonyms "dress" and "frock" for lexical cohesion. Collocation uses related words that typically go together or tend to repeat the same meaning. An example is the phrase "once upon a time".

\section{Types of References in Text}

\section{Backward Reference:}

The most common cohesive device in texts is the backward reference to something that has been mentioned before. The technical term for this type of reference is anaphora. Three examples of anaphoric reference are:

Use of a pronoun to refer back to an already mentioned noun.

$>$ Use of the definite article to qualify a noun that has already been introduced with' the indefinite article.

$>$ Substitution of an already mentioned noun by a synonym or hyponym.
Here are examples of each:

$>$ My sister's on the phone. She says she needs the drill that she lent us.

> When I looked out of the window yesterday, I saw a man and a woman standing by the gate. The man was wearing a hooded jacket and the woman was carrying a basketball bat.

$>$ There was so much delicious food on display, but I'm on a diet so I had to stick to the salad.

Some other examples: replacing "a taxi driver" with the pronoun "he" or "two girls" with "they." Another example can be found in formulate sequences such as "as stated previously" or "the aforementioned."

\section{Forward Reference:}

Another common cohesive device is forward reference or cataphora. Here are two examples of cataphoric reference:

$>$ Perhaps I shouldn't tell you this, but when I was young I had hair down to my waist!

Please send your reply to the following address

D Here he comes, our award-winning-host... He is John Doe!

Some sentences may also contain cataphoric ties connecting up with what follows; but these are very rare and are not very necessary to the creation of text.

This may interest you. A new vet doctor is in town.

It never should have happened. The security guard left his duty post!

The underlined sentences (d) and (e) give signals that the listener should expect to hear something else. These imply that cataphoric ties sensitize listeners or readers to on-coming information.

There is one more referential device, which cannot create cohesion: Exophoric reference. This is used to describe generics or abstracts without ever identifying them (in contrast to anaphora and cataphora, which do identify the entity and thus are forms of endophora): e.g. rather than introduce a concept, the writer refers to it by a generic word such as "everything". The prefix "exo" means "outside", and the persons or events referred to in this manner will never be identified by the writer. Halliday and Hasan considered exophoric reference as not cohesive, since it does not tie two elements together into a text (Halliday \& Hassan, Hoey, Silvia et al. 
References are signals marking the identity between what is being said and what has been said before. They have been brought together here because they have in common a "diectic" reference, that is, they point back (anaphoric) or forward (cataphoric) in discourse.

Halliday and Hasan give explanation of anaphora using the following examples:

Many students never improve.

They get no advice and therefore

They keep repeating the same mistakes. It's a terrible shame. (Halliday and Hasan, 6)

In the second sentence, "they" and "they" anaphoric ally refer to students. "It's" in the third sentence refers to the situation in which the students find themselves not getting advice and repeating same mistakes.

Generally, a given instance of reference is either exophoric or endophoric. While "exophora" is a reference to something outside the text, "endophora" is a reference to something within the text. It is also possible, for reference to be both exophoric and endophoric at the same time. However, it must be emphasized that the specific linguistic type of reference is by definition endophoric. Put more clearly, only endophoric reference is cohesive. Although exophoric reference contributes to the creation of text - by linking the language within the context of situation - it does not contribute to the integration of one passage with another to enable the two to come together to form part of the same text.

Below are also some examples of cataphoric ties:

1. This should interest you, if you are still keen on boxing. The world heavyweight championship is going to be held in Chicago next June, so you should be able to watch it live.

The first sentence underlined gives the prelude or signals that the listener should expect to hear something else.

2. Here is the news. A diplomat was kidnapped last night in London.

3. It never should have happened. She went out and left the baby unattended.

4. My arguments are as follows:... etc

These underlined sentences two (2) to four (4) give signals that the listener should expect something else.
These also imply that cataphoric ties sensitize listeners or reader to on-coming information.

\section{Ellipsis}

Ellipsis is another cohesive device. It happens when, after a more specific mention, words are omitted when the phrase needs to be repeated. A simple coversational example: (a) where are you going? (b) to dance. The full form of B's reply would be : "I am going to dance".

Ellipsis is most commonly used to avoid repetition and to indicate the omission of a repeated word or phrase. Some ellipses are dependent on linguistic context as shown below:

I am happy if you are (happy)

Mary is dusting the furniture

Because Alice won't (dust the furniture)

In the sentences one (1) and three (3), the word "happy" and the phrase "dust the furniture" are put in brackets. They indicate ellipsis/omission of repeated word or phrase. This ellipsis depends on linguistic context. Consider also for instance:

1. Would you like an apple? Ihave twelve.

"Ihave twelve" implies repetition of the word "apple"

2. Do you have need for admission? There are four vacancies.

Here also, "there are four "vacancies" implies repetition of the word "admission

Ellipsis not dependent on linguistic context:

Serves you right - for it serves you right

Beg your pardon - 1 beg your pardon

Sony I couldn't be there - I am sorry, I couldn't be there.

Good to see you - its good to see you

Looking for somebody? - are you looking for somebody etc.

\section{Substitution}

In substitution, a word is not omitted, as in ellipsis, but is substituted for another, more general word. For example, "which ice-cream would you like" - "I would like the pink one", where "one" is used instead of repeating "ice-cream". This works in a similar way with pronouns which replace the noun. For example "ice-cream: is a noun, and its pronoun could be "it", as in, "I dropped the ice-cream because it was dirty". 
Other examples include:

$>$ Joan already knows. Everybody does.

$>$ "Does" in the second phrase substitutes for "knows".

$>$ Everybody buys from here. Even, the poor people do.

$>$ "Do" in the second phrase substitutes for "buys" in the first sentence.

\section{Transitional Signals in Text Comprehension}

An important way to keep the reader on track is to post a notice of directions. Schwartz, in her Interactive Writing, declares that just as the roads have signs (road furniture) curves ahead, straight on (Royal Oak 10 miles, Toledo 130, or T- junction, slow down), so too, writers can direct readers. She identifies seven (7) basic kinds of transitional signals thus:

\begin{tabular}{|c|c|c|}
\hline $\begin{array}{l}\text { Kinds of } \\
\text { Signals }\end{array}$ & Symbols & $\begin{array}{c}\text { Examples of Transitional } \\
\text { Words }\end{array}$ \\
\hline Addition & + & $\begin{array}{l}\text { And, furthermore, } \\
\text { additional, in addition }\end{array}$ \\
\hline Alternative & & $\begin{array}{l}\text { On the other hand, but, } \\
\text { however, }\end{array}$ \\
\hline Contrast & 1 & Yet, different, in contrast, \\
\hline Equation & @ & $\begin{array}{l}\text { For example, for instance, } \\
\text { to illustrate }\end{array}$ \\
\hline Conclusion & $\$$ & $\begin{array}{l}\text { Therefore, we conclude, } \\
\text { thus: }\end{array}$ \\
\hline Chronology & \# & $\begin{array}{l}\text { First, second, meanwhile, } \\
\text { afterwards, then, etc. }\end{array}$ \\
\hline
\end{tabular}

The "addition" word signals the reader to continue straight ahead. The "alternative" words alert the readers to a possible alternative "or not to be". The "contrast" words show that a qualification is coming up or that the other side of the issue will now be presented. Equation words signal a definition or restatement, that is "a paraphrase". "Example" words indicate that the writer will stop getting ahead in order to develop contention by giving details about one case. It has been noted that while "equation words signal something at the same level of abstraction, "example" words signal that a more specific case is coming up. "Conclusions" tell the reader that the writer is about to look around to encapsulate the previous argued section. Finally, "chronology" words are special kinds of "example words"; they not only mark new (though addition) section but also show its order in the text (Schwartz, 4). From the foregoing, therefore, it is obvious that the main function of transitional signals is to direct the reader in the process of reading in order to arrive at desired "comprehension destination".

In slight contrasts, Jordan grouped the main connectives according to the similarity of their meaning with three basic connectives "and", "or" and "but". He explicates them as follows:

\section{And}

A. Listing or enumeration (indicates a cataloguing of what is -being said; most enumeration belong to a clearly defined "set"): first, furthermore, finally, one, two, three, etc.

Firstly, second(ly), third(ly), etc.

Above all

Last but not least

Mark the end of and ascending order

First and foremost

First and most importantly Mark the beginning of a descending

To begin, start with, in the second place, moreover, and to conclude next, then, afterward, lastly, finally - -

B. Addition (to what has been previously indicated: (1) reinforcement (includes confirmation)

Also, again, furthermore, moreover, then, in addition, besides, above all, too, as well as).

Equation (similarity with what has (preceded): equally, likewise, similarly, corresponding, in the same way, etc.

Note: either, neither, nor, not only --- (but) also --neither --- nor --- from the point of view of meaning, these are often the negative equivalents of "and." "Never" leaves the series open for further additions, whereas "nor" concludes it.

The truth of a previous assertion may be confirmed or contradicted by: indeed, actually, in (actual) fact, really, in real...

2. Transition (can lead to a new stage in the sequence of thought): now, with reference / respect / regard to / regarding.

Let us (now) turn to.... As far / as to (often used when discussing something briefly. 
International Journal of Trend in Scientific Research and Development (IJTSRD) ISSN: 2456-6470

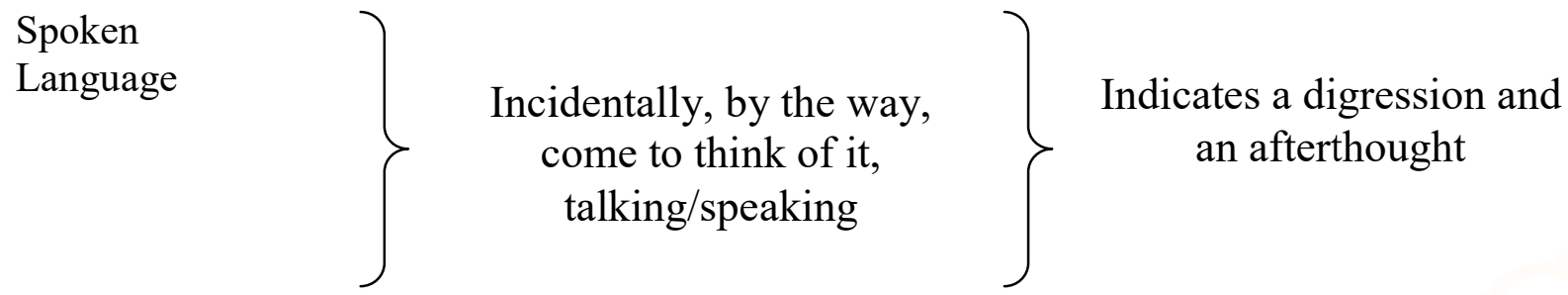

\section{Understanding Summary and Comprehension Passages Using Cohesive Devices}

Many students have difficulty understanding what they read. Some factors are responsible for this difficulty. They don't understand the meaning and purpose of connectives. They also lack ability to identify the functions of anaphoric and cataphoric ties in given passages. The purpose of connective is to enable the reader to find the conceptual relationships between the ideas and events expressed in the text. The four paragraphs below are illustrative of the anaphoric and cataphoric ties/explicit and implicit connectives:

The press is a general term for all types of printed newspapers and periodicals. It is an asset as well as a menace to society. Like many things in this world, it has its good and bad sides, no society can shut it down and thrive.

The press has its aims and objectives which it follows comes what may. Anyone who wants to be abreast of current affairs or notable events in his society must resort to reading printed materials, apart from watching the television. In fact, the press serves more people than the electronic media do. Newspaper and periodicals go where the television cannot. Printed material goes even to the remotest areas of the country.

Institutions of learning disseminate information. However, not all cities, towns and villages have these institutions, but the print media can be used to disseminate information to people in these areas.

Governments, institutions, and organization have their policies, programmes and activities for the smooth running of their affairs. At times, only those in authority reap the benefits. Subordinates are often afraid to criticize the authorities. Their best bet is to resort to the print media which become their mouth piece. Thus, what the oppressed cannot do, the print media do without fear or favour.
The pronoun "it" in the second sentence of paragraph 1 refers back anaphoric ally to the noun phrase "the press" in the first sentence. The pronoun "it" is

therefore a presuppose referring back to "the press". In paragraph 2 , the pronoun "its" is synonymous with "printed materials", "the press", "newspaper", periodicals and printed media".

The understanding that these four concepts mean the same thing as "its" in paragraph 2, keeps the reader abreast of the functions of the press, which is the main subject being discussed.

Similarly, pronoun "their" in sentence I, paragraph 4, refers anaphoric ally to the Government, Institutions and organizations. Pronoun "their" in the penultimate sentence in paragraph 4 , refers anaphoric ally to the subordinates and refers cataphorically to the "oppressed." Therefore, ability to identify anaphoric and cataphoric relationships in textual cohesion which link one sentence to other is of paramount importance.

\section{CONCLUSION}

It was discovered that effective writing and efficient comprehension are functions of cohesive relations that exist among the linguistic elements of any written text. Hence, this article advocates sensitivity to the network of cohesive relations as the bedrock for understanding written text. Writers should be ${ }^{-}$abreast with how to tie English sentences together clearly and naturally with the appropriate cohesive devices.

The reader, as an active collaborator with the writer, is a major player in the literary game. The text must cohesively hang together to enable him to "trust the text enough" so as to make sense of it. In other words, the text must contain enough cohesive ties that could foster understanding of it by the consumer (reader), In text comprehension, therefore, writers and readers in their collaborative roles in the literary "market" should be abreast with other signals to ensure clear understanding of texts. 
International Journal of Trend in Scientific Research and Development (IJTSRD) ISSN: 2456-6470

\section{REFERENCES}

1. Fareed Hammed Hamza and Hasan Hadi Mahdi. Cohesion and Coherence in English and Arabic:

A Cross-Theoretic Study. British Journal of English Linguistics Vol. 5, No. 3, May, 2017. Published by European Centre for Research Training and Development UK (www.eajournals.org)

2. Gutwinski, W. Cohesion in Literary Texts. The Hague: 1976.

3. Hallidy, M. A. K. and Hasan, R. Cohesion in English. London. Longman, 1976. 1- 13.

4. Indah Wardaty Saud. The Use of Cohesive Device in Writing, Cause and Effect Essay. University of Muhammadiyah Gorontalo. Volume 6, Number I, February, 2015.

5. Irwin, J. W. (ed) Understanding and Teaching Cohesion Comprehension. London: International Reading Association Inc, 1986.
6. Kennedy, Mary Lynch Ed. Theorizing Composition. Greenwood Press, 1998. DVD.

7. Moe, A. J. '"Cohesion and Comprehension of Texts". Journal of Reading, (1979) 16-23.

8. Osundare, N. "From Oral to Written: Aspects of the Socio-Stylistic Repercussion of Transition". Journal of African and Comparative Literature (1987), 1-13.

9. Roy P. Clark: Writing Tools: 50 Essential Strategies for Every Writer, 2006. DVD.

10. Schwartz, H. J. Interactive Writing. New York: CBS College Publishing, 1985.

11. Silvia Arnis: Grammatical and Lexical Cohesion. Available at http://www, academia.edu/2344329 Grammatical and Lexical Cohesion. Text modified on 20 February, 2016. DVD.

12. Wayne C. Booth and Marshall W. Gregor. The Harper and Row Rhetoric: Writing as Thinking/Thinking as Writing, 1987. DVD. 